\title{
$\mathrm{M}|\mathrm{R}| \mathrm{S}$ Internet Journal Nitride Semiconductor Research
}

\section{Strain relaxation in GaN layers grown on porous GaN sublayers}

\author{
M. Mynbaeva ${ }^{1}$, A. Titkov ${ }^{1}$, A. Kryzhanovski ${ }^{1}$, I. Kotousova ${ }^{1}$, A.S. Zubrilov ${ }^{1}$, V.V. Ratnikov ${ }^{1}$, V. Yu. \\ Davydov $^{1}$, N.I. Kuznetsov ${ }^{1}$, K. Mynbaev ${ }^{1}$, D.V. Tsvetkov ${ }^{2}$, S. Stepanov ${ }^{2}$, A.Cherenkov ${ }^{2}$ and V.A. \\ Dmitriev $^{3}$ \\ ${ }^{1}$ Ioffe Physical-Technical Institute, \\ ${ }^{2}$ Crystal Growth Research Center, \\ ${ }^{3}$ Technologies and Devices International, Inc.,
}

(Received Saturday, August 28, 1999; accepted Wednesday, November 10, 1999)

We have studied epitaxial GaN layers grown by hydride vapour phase epitaxy (HVPE) on porous $\mathrm{GaN}$ sublayers formed on $\mathrm{SiC}$ substrates. It was shown that these layers can be grown with good surface morphology and high crystalline quality. X-ray, Raman and photoluminescent (PL) measurements showed that the stress in the layers grown on porous $\mathrm{GaN}$ was reduced to $0.1-0.2 \mathrm{GPa}$, while the stress in the layers grown directly on $6 \mathrm{H}-\mathrm{SiC}$ substrates remains at its usual level of about $1 \mathrm{GPa}$. Thus, we have shown that growth on porous GaN sublayer is a promising method for fabrication of high quality epitaxial layers of $\mathrm{GaN}$ with low strain values.

\section{Introduction}

Recently, much effort has been made to develop a technology that would allow growth of residual stress-free epitaxial layers of GaN. Poor lattice match and difference in thermal expansion coefficients with foreign substrates being currently used for epitaxial growth of $\mathrm{GaN}$ layers make these layers quite strained, with average value of biaxial stress ranging up to $1 \mathrm{GPa}$. This stress affects both structural and electric properties of the layers and devices built on such layers cannot take full advantage of intrinsic properties of GaN. Porous materials seem to offer a good opportunity for epitaxial growth of high-quality epitaxial films, as they are expected to be able to substantially reduce the strain in layers grown on top of them [1]. Several attempts to use porous $\mathrm{Si}$ as a substrate for epitaxial growth of different materials have been already reported to be successful [2] [3]. Further development of this idea naturally implies using a porous layer of native material as a substrate for epitaxial growth. In this paper we for the first time report on the successful growth of epitaxial GaN layers on porous $\mathrm{GaN}$ sublayer formed on $\mathrm{SiC}$ substrates. The stress in these layers as compared to $\mathrm{GaN}$ grown directly on $6 \mathrm{H}$ $\mathrm{SiC}$ substrates was investigated by x-ray diffractometry, Raman spectroscopy and PL measurements. As a result, we show that the value of the biaxial stresses in $\mathrm{GaN}$ layers grown on porous sublayers is essentially less than that in GaN layers grown directly on SiC substrates.

\section{Experimental}

The original GaN layers were n-type with concentration $\mathrm{N}_{\mathrm{d}}-\mathrm{N}_{\mathrm{a}}$ of about $10^{17} \mathrm{~cm}^{-3}$, grown by the HVPE technique [4] [5]. GaN epitaxial layers were grown using an HVPE growth machine equipped with a resistively heated furnace. In a horizontal open-flow reactor, $\mathrm{HCl}$ gas reacted with liquid $\mathrm{Ga}$ metal to form $\mathrm{GaCl}$ gas, which was transported to the growth zone of the reactor and reacted with $\mathrm{NH}_{3}$ resulting in GaN deposition on SiC substrates. Argon was used as a carrier gas. The growth temperature was kept between 950 and $1050^{\circ} \mathrm{C}$. The substrates used were $6 \mathrm{H}-\mathrm{SiC}$. GaN layers being deposited on (0001)Si face of the substrates were single crystal exhibiting full width at a half maximum (FWHM) of x-ray $\omega$-scan rocking curve of less than 200 arc sec. These layers were anodized in an HF solution under ultraviolet light excitation to form porous $\mathrm{GaN}$, as described elsewhere [6]. The pore size was less than 0.3 $\mu \mathrm{m}$. Epitaxial growth of cap GaN layers on porous sublayers was conducted by the same HVPE procedure.. The general characterisation of the layers was carried out using scanning electron microscopy (SEM), atomic force microscopy (AFM), reflection high energy electron diffraction (RHEED) and capacity-voltage measurements of Schottky barriers formed by mercury probe. 


\section{Results and Discussion}

We have observed successful epitaxial growth of the cap $\mathrm{GaN}$ layers with thicknesses ranging from 2 up to $70 \mu \mathrm{m}$ on porous sublayers with thicknesses from 1 to $10 \mu \mathrm{m}$. A comparison study of the properties of GaN layers grown on porous sublayers and directly on $\mathrm{SiC}$ substrates was conducted on $3 \mu \mathrm{m}$-thick layers, as this thickness is used in most of current devices based on GaN layers.

Figure 1 presents a SEM image of a cleaved edge of $\mathrm{GaN} /$ porous $\mathrm{GaN}$ structure on $\mathrm{SiC}$ substrate. It is clearly seen that $\mathrm{GaN} /$ porous $\mathrm{GaN}$ interface is abrupt, and pores do not lead to the formation of any visible defects in the cap epitaxial layer. The as-grown surface of cap epitaxial layers was smooth if their thickness did not exceed $10 \mu \mathrm{m}$. The AFM study of the surface roughness showed the presence of growth steps as high as $5 \mathrm{~nm}$ (Figure 2).

The as-grown surface of cap epitaxial layers was also studied by RHEED after exposition to air. Figure 3 presents an RHEED image of a surface of cap $\mathrm{GaN}$ layer with $3 \mu \mathrm{m}$ thickness. Vertical rods point out to good flatness of the surface, while Kikuchi lines indicate high crystalline quality of the surface.

The crystal quality of GaN layers was studied through the measurements of a FWHM of the x-ray diffraction rocking curves. The angular distribution of the $\mathrm{x}$-ray diffraction corresponding to (0002), (0004) and (1124) reflections was measured by means of triplecrystal diffractometry on $\mathrm{CuK}_{\alpha 1}$ radiation under conditions of symmetrical and asymmetrical Bragg-geometry as described elsewhere [7]. Diffraction curves were measured for $\omega$ - and $\omega$ - $2 \theta$ scanning modes $\left(\omega_{\eta-}\right.$ and $\omega_{\alpha-}$ FWHM, respectively). On the basis of measured parameters, the components of the microdistortion tensor $\varepsilon_{\mathrm{zz}}$ and $\varepsilon_{\mathrm{zx}}$ were evaluated and the average size of grains (average size of the coherent scattering areas) both in the epitaxial layer plane $\tau_{\mathrm{x}}$ and along the c-axis $\tau_{\mathrm{z}}$, was determined. The data obtained on a $3 \mu \mathrm{m}$-thick cap GaN layer grown on a porous sublayer with the same thickness and on a $3 \mu \mathrm{m}$-thick GaN layer grown directly on $\mathrm{SiC}$ substrate are presented in Table 1.

$\mathrm{X}$-ray diffraction data showed that both original $\mathrm{GaN}$ layers grown on $6 \mathrm{H}-\mathrm{SiC}$ substrate and cap $\mathrm{GaN}$ layers grown on porous $\mathrm{GaN}$ had single crystalline structure of wurtzit GaN. For both type of layers the specific features of X-ray diffraction were as follows: $\omega_{\eta}>\omega_{\alpha}$ for all reflections; $\omega_{\eta}{ }^{0002}>\omega_{\eta}{ }^{0004}$; $\omega_{\eta}{ }^{0002}>\omega_{\eta}{ }^{11 \overline{2} 4}$ for grazing incidence geometry of asymmetric diffraction (11) 4$) ; \quad \omega_{\alpha}{ }^{0004} / \omega_{\alpha}{ }^{0002} \sim \operatorname{tg} \theta^{0004} /$ $\operatorname{tg} \theta^{0002}$. Thus, the diffraction spot was anisotropic and elongated along the (0001) plane of the layer surface.
From the above features of the x-ray rocking curves we conclude, according to [5] and [7], that the observed diffraction anisotropy is caused by both the anisotropy of grain size $\tau_{\mathrm{x}}<\tau_{\mathrm{z}}$ of the mosaic structure of the layers studied and specific defects in grains (screw and edge dislocations). The broadening of diffraction curves obtained through a conventional $\omega$ - scan for the GaN layers grown on porous sublayer results from the variation in the mosaic spread and may be related to reduced grain size in these layer. The small FWHM values of the $\omega-2 \theta$ rocking curves prove the high crystalline quality of the cap layers.

The $\mathrm{N}_{\mathrm{d}}-\mathrm{N}_{\mathrm{a}}$ concentration in cap layers as measured by mercury probe at $1 \mathrm{MHz}$ testing frequency ranged from $1 \times 10^{15}$ to $1 \times 10^{17} \mathrm{~cm}^{-3}$.

The biaxial stresses in cap GaN layers as compared to those in $\mathrm{GaN}$ layers grown directly on $6 \mathrm{H}-\mathrm{SiC}$ substrates were estimated according to the results of x-ray, Raman scattering and PL measurements. The measurements were performed on a $3 \mu$ m-thick cap GaN layer grown on $3 \mu \mathrm{m}$-thick porous $\mathrm{GaN}$ sublayer, and on a 3 $\mu \mathrm{m}$-thick $\mathrm{GaN}$ layer grown directly on $6 \mathrm{H}-\mathrm{SiC}$ substrate during the same growth process.

As far as $\mathrm{x}$-ray characterisation was concerned, the calculations of biaxial stresses and strain along $c$-axis in $\mathrm{GaN}$ layers were performed using measured values of radius of curvature $\mathrm{R}$ and lattice constant $c$. The $\mathrm{R}$ value was measured as described elsewhere [8], and the measurements of lattice constants were performed using a triple crystal modification of the Bond method [9]. The measured values of $\mathrm{R}$ and lattice constant $c$ $(\Delta c= \pm 0.0001 \mathrm{~A})$ as well as calculated values of biaxial stresses $\sigma_{\mathrm{a}}$ and strain $\varepsilon_{\mathrm{c}}=\left(c-c_{0}\right) / c_{0}$, where $c_{0}=5.1850 \mathrm{~A}$ is a relaxed lattice constant for $\mathrm{GaN}$ [10], are summarised in Table 2. The data presented in Table 2 show that both $\mathrm{GaN}$ layers grown directly on $\mathrm{SiC}$ substrate and on porous sublayers were tensile $\left(\sigma_{\mathrm{a}}>0\right)$, but tensional biaxial stress and strain in cap layers were significantly reduced as compared to epitaxial layers grown on $6 \mathrm{H}-$ $\mathrm{SiC}$.

Raman scattering measurements were carried out at room temperature using an $\mathrm{Ar}^{+}$laser $(\lambda=488 \mathrm{~nm})$ as a source of excitation. The scattered radiation was analysed by a double grating monochrometer with computercontrolled systems for scanning and data acquisition. A back scattering geometry with the $\mathrm{z}$ direction parallel to the optical axis of the crystal was employed. Figure 4 presents Raman spectra near $\mathrm{E}^{2}$ mode for a GaN layer grown directly on $6 \mathrm{H}-\mathrm{SiC}$ substrate (a) and for a cap GaN layer (b) grown on porous GaN. The shift of the $\mathrm{E}^{2}$ line towards lower frequencies as compared to its position for a strain-free sample (which in this case was a 
"bulk" GaN sample grown by HVPE under conditions similar to those described in [11] with $\mathrm{E}^{2}$ mode peak at $567.8 \mathrm{~cm}^{-1}$ ) points out to a tensile character of the inplain stress in the samples studied. At the same time, from Figure 4 it is clearly seen that the shift of the $E^{2}$ line for a cap layer grown on porous $\mathrm{GaN}$ is essentially less than that for a $\mathrm{GaN}$ layer grown on $6 \mathrm{H}-\mathrm{SiC}$ substrate. As estimated from Raman data according to [12], the cap GaN layer had in-plain stress of $\sigma \approx 0.20 \mathrm{GPa}$. Fitting the $\mathrm{E}^{2}$ line to the Lorenz function gives the following values for FWHM's in the samples studied: 3.7 $\mathrm{cm}^{-1}$ for GaN layers grown on $6 \mathrm{H}-\mathrm{SiC}$ substrate and 3.1 $\mathrm{cm}^{-1}$ for cap $\mathrm{GaN}$ layers grown on porous sublayer, again supporting the improvement in the crystalline structure of these layers as compared to GaN layers grown directly on $\mathrm{SiC}$ substrates.

The photoluminescence was excited by a pulsed nitrogen laser with $2 \mathrm{~kW}$ pumping power. The position of the maximum of luminescence spectra taken at $77 \mathrm{~K}$ corresponded to neutral donor-bound exciton recombination in GaN [13]. This exciton peak maximum for the cap $\mathrm{GaN}$ layers was blue-shifted by $22 \mathrm{meV}$ relative to that for $\mathrm{GaN}$ layers grown on $6 \mathrm{H}-\mathrm{SiC}$, whose maximum corresponded to $3.449 \mathrm{eV}$. According to [13], this clearly pointed to a reduction of stress in the cap layer by $\sim 0.9 \mathrm{GPa}$. Also, the FWHM of the excitonic peak for the cap GaN layer was reduced to as low as $20 \mathrm{meV}$ compared to that of the GaN layer grown on $6 \mathrm{H}-\mathrm{SiC}$ substrate (FWHM of $32 \mathrm{meV}$ ). This feature indicated an improvement in the crystalline structure of GaN layers grown on porous $\mathrm{GaN}$.

Comparison analysis of the x-ray, Raman and PL data shows that the value of the biaxial stresses in cap GaN layers grown on porous sublayers is substantially less than that for the GaN layers grown directly on $6 \mathrm{H}-$ $\mathrm{SiC}$ substrates. The discrepancy in the absolute values of the biaxial stresses as measured by different methods can be possibly attributed to the fact that these different methods were calibrated using different standards for "strain-free" GaN.

\section{Conclusion}

Summarizing, we grew high quality GaN layers on porous $\mathrm{GaN}$, for the first time. Porous $\mathrm{GaN}$ was formed from $\mathrm{GaN}$ layer deposited on $6 \mathrm{H}-\mathrm{SiC}$ substrate. The crystal structure and stress in GaN layers grown by HVPE on porous GaN was investigated. AFM and RHEED studies showed that the layers possessed smooth surfaces, while PL and Raman measurements pointed to high crystalline quality of the layers. Special emphasis was put on studying the biaxial stresses and strain in the layers. X-ray, Raman and PL measurements showed that the stress in the layers grown on porous $\mathrm{GaN}$ was reduced to 0.1-0.2 GPa. Thus, we have shown that porous sublayer allows the growth of high quality $\mathrm{GaN}$ with substantially reduced strain as compared to those grown directly on $6 \mathrm{H}-\mathrm{SiC}$ substrates.

\section{ACKNOWLEDGMENTS}

The authors would like to thank Yu. Melnik for GaN epitaxial layers provided for this study, I. Goncharuk and A. Smirnov for Raman measurements, N. Seredova for PL characterizations, V. Busov for SEM characterization and V. Shuman and I. Nikitina for helpful discussions. The work was partially supported by Russian Ministry of Science through a "Surface Atomic Structures" program and by INTAS grants \#96-1031 and \#96-2131.

\section{REFERENCES}

[1] V.Bondarenko, L.Dolgyi, N.Vorozov, V.Yakovtseva, V.Levchenko, L.Postnova, Perspectives, science and technologies for novel silicon on insulator devices, NATO Advanced Research Workshop, Conf. Abstracts p.p.15-16, (1998), Kiev, Ukraine

[2] S. Konaka, M. Tabe, T. Sakai, Appl. Phys. Lett. 41, 8688 (1982).

[3] Y. Kao, K. Wang, B. Wu, T. Lin, C. Nien, D. Jamieson, G. Bai, Appl. Phys. Lett. 51, 1809-1811 (1987).

[4] YuV Melnik, IP Nikitina, AS Zubrilov, AA Sitnikova, YuG Musikhin, VA Dmitriev, Inst. Phys. Conf. Ser. 142, 863866 (1996)

[5] V. Dmitriev, K. Irvine, G. Bulman, J. Edmond, A. Zubrilov, V. Nikolaev, I. Nikitina, D. Tsvetkov, A. Babanin, A. Sitnikova, Yu. Musikhin, N. Bert, J. Cryst. Growth 166, 601-606 (1996).

[6] M. Mynbaeva, D. Tsvetkov, Inst. Phys. Conf. Ser. 155, 365-368 (1997).

[7] A. Usikov, V.V. Ratnikov, R. Kyutt, W. V. Lundin, B. Pushnyi, N. M. Shmidt, M.P. Scheglov, MRS Internet J. Nitride Semicond. Res. 3, 42 (1998).

[8] G. Rozgonyi, P. Petroff, M. Panish, J. Cryst. Growth 27, 106-117 (1974).

[9] P. Fewster, N. Andrew, Appl. Cryst. 28, 451 (1995).

[10] M. Leszczynski, T. Suski, P. Perlin, M. Teisseyre, J. Grzegory, M. Bockowski, Yun, S. Porowski, J. Major, J. Phys. D 28, A149-A153 (1995).

[11] Yu.V. Melnik, K.V. Vassilevski, I.P. Nikitina, A.I. Babanin, V. Yu. Davydov, V.A. Dmitriev, MRS Internet J. Nitride Semicond. Res. 2, 39 (1997).

[12] V. Davydov, N. Averkiev, I. Goncharuk, D. Nelson, I. Nikitina, A. Polkovnikov, A. Smirnov, M. Jacobson, O. Semchinova, J. Appl. Phys. 82, 5097 (1997).

[13] W Rieger, T Metzger, H Angerer, R Dimitrov, O Ambacher, M Stutzmann, Appl. Phys. Lett. 68, 970 (1996). 


\section{FIGURES}

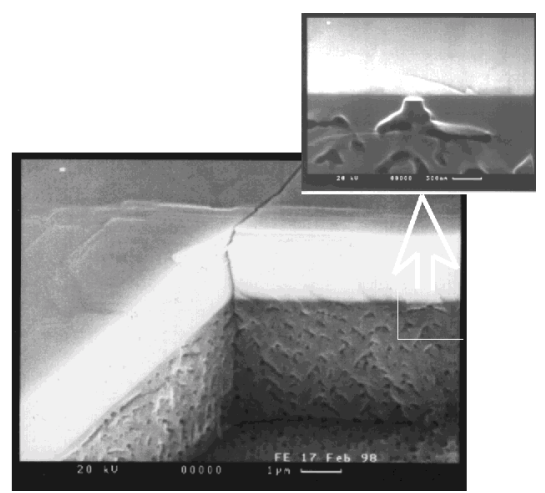

Figure 1. SEM image of a cleaved edge of $\mathrm{GaN} /$ porous $\mathrm{GaN} /$ $\mathrm{SiC}$ structure ( $\mathrm{SiC}$ is not shown).
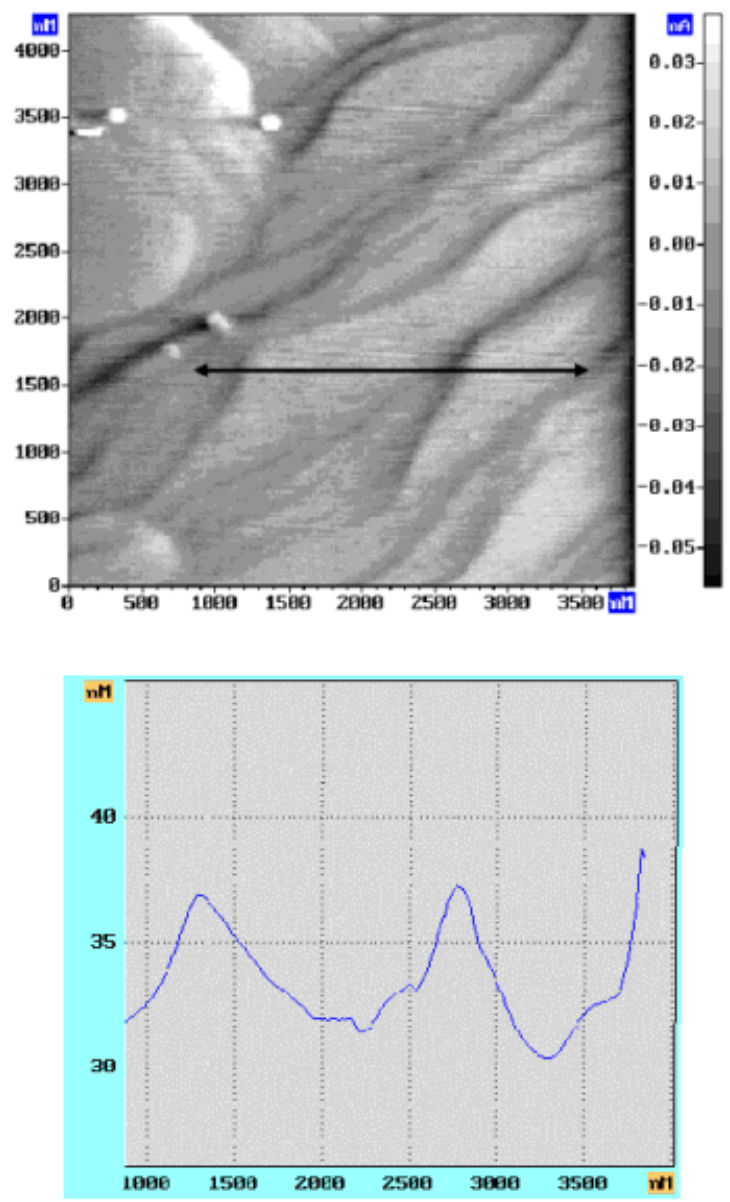

Figure 2. AFM image of a surface of a GaN layer grown on porous GaN (top) and an AFM profile of the surface (bottom) corresponding to a line as indicated by arrow on top AFM picture. As seen from the profile, the growth steps do not exceed $5 \mathrm{~nm}$.

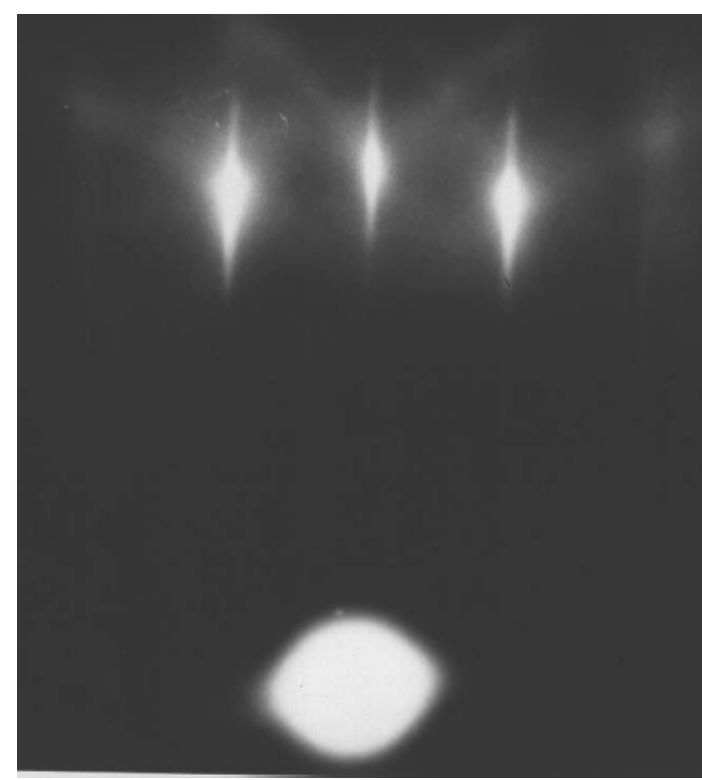

Figure 3. RHEED pattern obtained from as-grown GaN layer grown on porous $\mathrm{GaN}$.

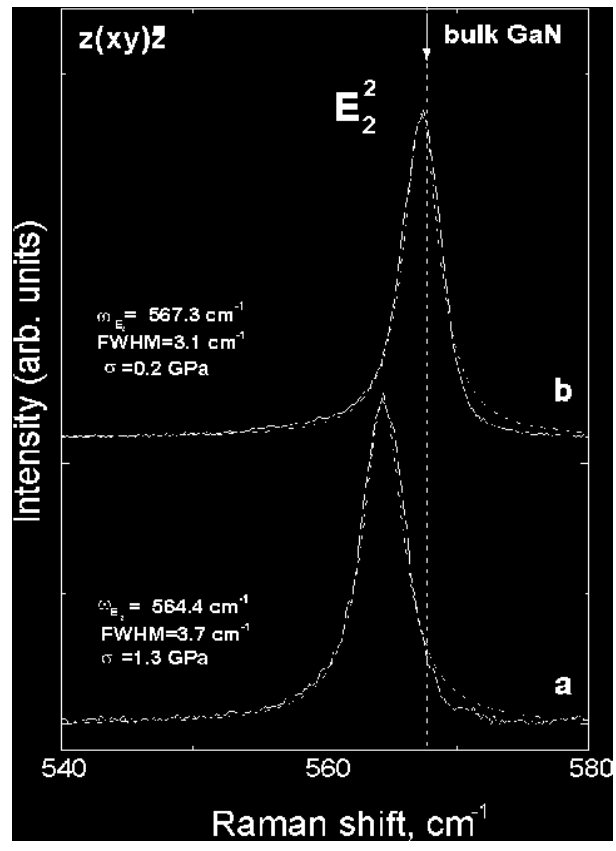

Figure 4. Raman spectra near $\mathrm{E}^{2}$ mode for a GaN layer grown directly on $6 \mathrm{H}-\mathrm{SiC}$ substrate (a) and for a $\mathrm{GaN}$ layer (b) grown on porous $\mathrm{GaN}$. 


\section{TABLES}

Table 1. FWHMs of rocking curves, microdistortion tensor components and grain sizes in the structures studied.

\begin{tabular}{|c|c|c|c|c|c|c|c|c|}
\hline $\begin{array}{l}\text { Structure } \\
\text { type }\end{array}$ & $\begin{array}{c}\omega_{\eta}^{0002}, \\
\text { angle sec. }\end{array}$ & $\begin{array}{c}\omega_{\alpha}{ }^{0002}, \\
\text { angle sec. }\end{array}$ & $\begin{array}{c}\omega_{\eta}{ }^{0004}, \\
\text { angle sec. }\end{array}$ & $\begin{array}{c}\omega_{\alpha}{ }^{0004}, \\
\text { angle sec. }\end{array}$ & $\varepsilon_{\mathrm{zz}}, 10^{-4}$ & $\varepsilon_{\mathrm{zx}}, 10^{-4}$ & $\tau_{x}, \mu m$ & $\tau_{\mathrm{z}}, \mu \mathrm{m}$ \\
\hline GaN/SiC & 136 & 23 & 130 & 38 & 1.22 & 3.10 & 1.14 & 4.85 \\
\hline $\begin{array}{l}\text { GaN/por- } \\
\text { GaN/SiC }\end{array}$ & 633 & 40 & 610 & 86 & 2.80 & 14.60 & 0.27 & 2.96 \\
\hline
\end{tabular}

Table 2. Radii of curvature, biaxial stresses, lattice constants and strain in the structures studied.

\begin{tabular}{|l|l|l|l|l|}
\hline $\begin{array}{l}\text { Structure } \\
\text { type }\end{array}$ & R, m & $\sigma_{a}, \mathrm{GPa}$ & $\mathrm{c}, \dot{A}$ & $\varepsilon_{\mathrm{c}}^{\exp }, 10^{-3}$ \\
\hline GaN/SiC & -6.5 & +0.64 & 5.1792 & -1.12 \\
\hline $\begin{array}{l}\text { GaN/por.- } \\
\text { GaN/SiC }\end{array}$ & -10.8 & +0.12 & 5.1801 & -0.94 \\
\hline
\end{tabular}

